\title{
The life span of Methodist ministers: an example of the use of obituaries in epidemiology
}

\author{
Tim Allison, Selwyn St Leger
}

Obituaries have occasionally been used in epidemiological studies, ${ }^{12}$ but their use gives rise to methodological problems. We aimed to highlight and investigate these problems in an historical cohort study of British Methodist ministers from two branches of the church. The Primitive Methodists came from a predominantly lower socioeconomic background, whereas the background of Wesleyan Methodists tended to be more privileged. ${ }^{3}$ So we aimed to examine differences in life span between groups performing the same work but coming from different socioeconomic backgrounds.

\section{Methods and Results}

A study population formed from consecutive obituaries forms a death cohort with people born in many different years and so will not be valid for epidemiological study. We avoided this problem by constructing historical birth cohorts, examining all available obituaries of Methodist ministers appearing between 1870 and 1985 and selecting by year of birth. We constructed four cohorts for comparison: Primitive ministers born 1850-1854; Wesleyan ministers born 1850-1854; Primitive ministers born 1880-1884; Wesleyan ministers born 1880-1884. Age at entering the ministry was noted and we attempted to record information on prior occupation, father's occupation, and cause of death. Those killed on active military service were excluded. Separate analyses were carried out with and without ministers who had served as foreign missionaries.

Obituaries may only record a biased sample of a population. We tackled this problem by using an additional data source and by assessing the completeness of the cohorts. The principal primary data sources were the annual minutes of the Methodist Conferences, ${ }^{4}$ but an additional secondary source was available for Primitive ministers, ${ }^{5}$ which had been compiled from a wide variety of primary sources. We assessed completeness by noting all those who became ministers in 1875 and 1905 and recording the proportion who had a subsequent obituary published. We constructed survival curves for the cohorts and calculated the statistical significance of differences using the log rank test.

The size of the cohorts and our estimates of their completeness were as follows:

Primitives 1850-1854, 113 ministers, 53\% complete; Wesleyans 1850-1854, 141 ministers, 53\% complete; Primitives 1880-1884, 305 ministers, 85\% complete; Wesleyans 1880-1884, 361 ministers, $78 \%$ complete.

Only 80 obituaries contained details of prior occupations or paternal occupation and cause of death was rarely mentioned. All the ministers in the study were men. The median age for entering the ministry, where recorded,
Department of Public Health, West Pennine Health Authority, Oldham

T Allison

University of Manchester, School of Epidemiology and Health Sciences, Manchester S St Leger

Correspondence to: Dr T Allison, 16 Lock Lane, Partington, Manchester M31 4PX.

Accepted for publication 19 October 1998

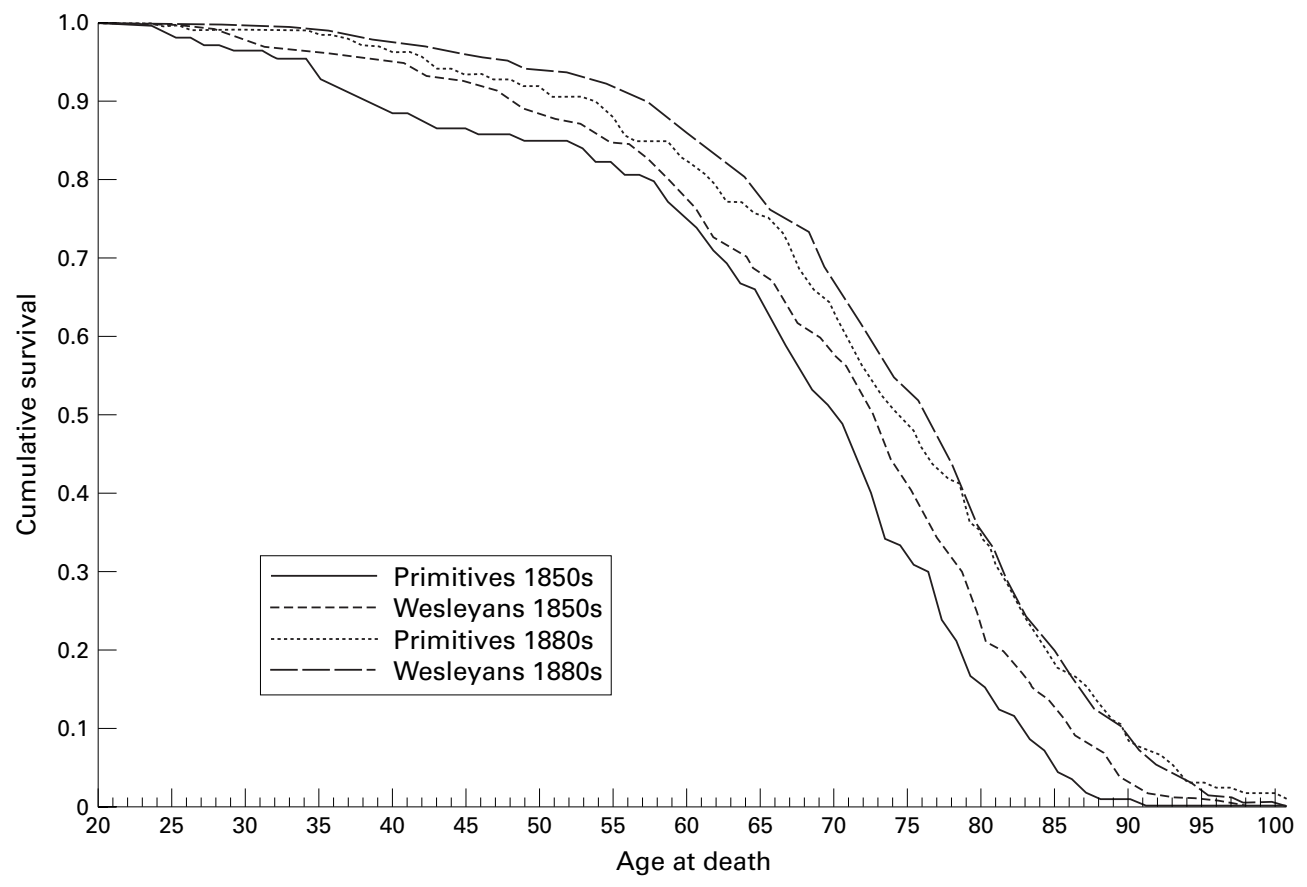

Figure 1 Methodist ministers'survival curves. 
was 25 for the 1880s Primitive cohort and 23 for the other three cohorts. However, the age at death in the 1850s Wesleyan cohort was significantly higher for those where a date of entering ministry was not recorded, suggesting that those with a date recorded may be a biased sample.

The survival of both Primitives and Wesleyans improved significantly between those born in 1850-1854 and those born in 1880-1884 (fig 1). Wesleyans from the 1850 s cohort had a significantly longer life span than did the 1850 s Primitives, but the difference between the 1880 s cohorts was not statistically significant. Analysis excluding missionaries made no difference to the results.

\section{Comment}

Obituaries can be used to construct historical cohorts in epidemiological research. However, the sample identified using obituaries may be incomplete and unrepresentative. Information other than the date of death may be absent and may be biased if present. Variations in age of entry to an occupation or activity may bias particular groups.
We tackled these problems by constructing a historical birth cohort, using an additional data source, assessing the completeness of the cohorts and noting age at entry to the profession. However, the extent of incompleteness of the cohorts and the lack of other information prevents us from coming to any significant conclusions. Other studies based on obituaries will probably encounter similar problems.

We would like to thank Professor John Pickstone, University of Manchester, for his historical advice.

Funding: none.

Conflicts of interest: none.

1 Blair A, Hayes MH. Mortality patterns among US veterinarians, 1947-1977: an expanded study. Int $\mathcal{f}$ Epidemiol 1982;11:391-7.

2 Wright DJM, Roberts AP. Which doctors die first? Analysis of BMF obituary columns. BMF 1996;313:1581-2.

3 Davies RE. Methodism. London: Epworth, 1963.

4 Primitive Methodist Church. Minutes made at the 51st 113th Annual Conference of the Primitive Methodist Connexion. London, 1870-1932; Wesleyan Methodist Church. Minutes of Several Conversations at the 127th - 189th Yearly Conference of the People Called Methodists. London, 18701932; Methodist Church. The Minutes of the Annual Conference. London: 1933-1990.

5 Leary W. Primitive Methodist Ministers and their stations from the commencement to 1932. 2nd ed. Chester: W Leary, 1981. 